\title{
Multiple Response Optimization of Three-Body Abrasive Wear Behaviour of Graphite Filled Carbon-Epoxy Composites Using Grey-Based Taguchi Approach
}

\author{
K. M. Subbaya ${ }^{1 *}$, N. Rajendra ${ }^{1}$, Y. S. Varadarajan ${ }^{1}$, B. Suresha ${ }^{2}$ \\ ${ }^{1}$ Department of Industrial \& Production Engineering, The National Institute of Engineering, Mysore, India \\ ${ }^{2}$ Department of Mechanical Engineering, The National Institute of Engineering, Mysore, India \\ Email: *kms_coorg@yahoo.com
}

Received April 11, 2012; revised May 20, 2012; accepted June 8, 2012

\begin{abstract}
The three-body abrasive wear behaviour of carbon fabric reinforced epoxy (C-E) composites has been evaluated by the addition of graphite $(\mathrm{G})$ particles as a secondary reinforcement. Three-body abrasive wear test were conducted using dry sand rubber wheel abrasion tester as per ASTM G-65 with three process parameters load, abrading distance and filler content. To assess the abrasive wear behaviour of particulate filled C-E composites satisfying multiple performance measure, grey-based Taguchi approach has been adopted. The experiments were designed according to Taguchi's orthogonal array $\left(\mathrm{L}_{27}\right)$. The grey relational analysis was applied to convert a multi response process optimization to a single response. Using analysis of variance, significant contributions of process parameters have been determined. The results indicate that the addition of graphite particles into C-E composite increased the wear resistance considerably. It was observed that highest wear resistance of C-E composite was achieved with incorporation of $10 \mathrm{wt} \%$ of graphite filler. Results indicate that the filler content and grit size of abrasive paper were found to be the most significant factor which has influence on the abrasive wear of C-E composite. The worn surface features were examined through scanning electron microscope to probe the wear mechanism.
\end{abstract}

Keywords: Composites; Three-Body Abrasion; Grey Relational Analysis; Scanning Electron Microscope

\section{Introduction}

Engineering polymers have attracted much interest in structural applications for many years, because of their superior properties such as light weight, strong, ease of fabrication and low cost [1]. In recent years much attention has been devoted to explore the potential advantage of thermoset matrices for new polymer composites [2]. One of such matrix is epoxy which has found a special place in the family of thermoset engineering polymers because of its excellent mechanical properties with chemical and corrosion resistance [3]. Polymer composites are subjected to abrasive wear in many applications. Abrasive wear as defined by ASTM, is due to hard particles or hard protuberances that are forced against and move along a solid surface. Wear, in turn, is defined as damage to a solid surface that generally involves progressive loss of material and is due to relative motion between that surface and a contacting substance or substances. Abrasive wear occurs when hard asperities on one surface move across a softer surface under load, pen-

"Corresponding author. etrates and remove material from the softer surface leaving grooves [4]. The tribological performance of composite material is usually related with the properties of their reinforcement [5]. One of the traditional concepts to improve the friction and wear behaviour of polymeric materials is to enhance their hardness, stiffness and their compressive strength and to reduce adhesion to the counterpart material [6-9]. Many investigations have shown that the incorporation of fiber reinforcement improved the wear resistance and reduced the coefficient of friction [10]. Mody et al. [11] in their investigation showed the simultaneous existence of parallel and perpendicular oriented carbon fibers in a woven configuration leads to a synergic effect on the enhancement of the wear resistance of composite. Carbon fiber is graphitized carbon with the hexagonal planes of its crystals aligned perpendicular to the fiber axis. The lubricating function of the graphitized carbon is thought to be responsible for the reduction of the friction coefficient and wear rate as the composite slide against the matting surface. Besides the lubricating function, carbon fiber also enhances the thermal conductivity and mechanical properties of poly- 
mer matrix which is believed to be beneficial to the wear resistance as well [12].

A notable advance in the polymer industry has been the use of fiber and particulate fillers as reinforcements in polymer matrices. Many researchers found that glass fiber and carbon fibers were effective reinforcements for distinct effect on the friction and wear behaviour of polymer composites [13]. The advantage of glass fiber includes low cost, high strength as well as high chemical resistance. On the other hand its low modulus, low fatigue resistance. Its self-abrasiveness and its poor interaction with some matrices limit this type of fiber for some tribological applications. Carbon fibers not only show a high strength and modulus but also have an excellent heat stability and chemical inertness [14]. Furthermore, carbon fiber is preferred as reinforcement/filler in tribocomposites because it imparts reinforcement, conductivity and better friction. However, these fibers have some disadvantages such as difficulty of uniform distribution, poor interfacial adhesion etc. [15]. The modification of tribological behaviour of fiber reinforced polymers by the addition of functional fillers has been reported by many researchers $[16,17]$. Particulate fillers are of considerable interest, not only in the economic point of view but also as modifiers especially in respect to improve physical properties of polymer. It is well documented in the literature that majority of fillers have a positive influence on mechanical properties [18]. Inorganic fillers like $\mathrm{SiC}, \mathrm{SiO}_{2}, \mathrm{Al}_{2} \mathrm{O}_{3}, \mathrm{MoS}_{2}$, graphite, addition into polymer composite can promote hardness, wear resistance and thin film formation on the counterpart during sliding wear process. Most of the findings are based on randomly oriented, unidirectional oriented or woven fabric reinforced polymer composites. Surface treatment of carbon fibers [19-21] is commonly used to improve the fiber-matrix adhesion, interfacial shear strength, etc. However, only few works are focussed on the effect of surface modification of filler on abrasive wear properties of fiber reinforced polymer composites. It is reported that silane coupling agent promotes the interfacial adhesion and interfacial toughness between glass fibers and polytetrafluoroethylene (PTFE) and largely enhance the tensile and tribological properties of glass PTFE composites [22,23].

Majority of research studied detailed experimental work with effect of one factor by keeping all other factors fixed, this approach is not advisable because in actual environment there will be combined effects of interacting factors influencing the abrasive wear. Hence in this study an attempt is being made to study the interacting effects of factors along with the main effect. To achieve this, design of experiments based on Taguchi method is adopted. This method is advocated by Taguchi and Konishi [24]. Taguchi's technique uses special design of orthogonal ar- rays to study the entire parameter space with only a small number of experiments. Taguchi's technique also helps in optimizing the critical parameters [25].

Carbon fabric reinforcement and graphite filler are good choice since in many applications both high modulus and high strength are desired. In the present work, the carbon fabric and graphite particles were treated with silane coupling agent and their effect on Tree-body abrasive wear of epoxy composites have been evaluated using multi response grey-based Taguchi method. The purpose of this work is to study the abrasion resistance of $\mathrm{C}-\mathrm{E}$ composite with silane treated graphite particles under three-body abrasion using silica sand of angular shape. It is expected that this research work can be helpful to the use of epoxy composites in practice.

\section{Experiment}

\subsection{Materials}

The composites investigated in the present study, consists of bi-directional carbon fabric of about $6-8 \mu \mathrm{m}$ diameter as reinforcement (T300). The carbon fiber surface is treated with silane coupling agent to improve adhesion between the matrix and fiber. Epoxy resin (LY556) with room temperature curing hardener (HY951 grade) with diluent DY021 (supplied by Hindustan Ciba Geigy) mix was employed for the matrix material. The graphite particles of average size of about $20-25 \mu \mathrm{m}$ were employed as filler material. The details of composites selected, measured density and hardness are listed in Table 1. Threebody wear test samples of size $25 \times 75 \times 2.5 \mathrm{~mm}^{3}$ were prepared from the laminate using a diamond tipped cutter.

\subsection{Barcol Hardness}

ASTM D2583 Barcol hardness test method [26] is used to determine the hardness of reinforced thermosets. The specimen is placed under the indentor of Barcol hardness tester and a uniform pressure is applied to the specimen until the dial indication reaches a maximum. The depth of penetration is converted in to absolute Barcol numbers. At least three specimens of each composition were tested and the average values were listed in Table 1.

Table 1. Composites selected for study.

\begin{tabular}{ccccc}
\hline Material (designation) & $\begin{array}{c}\text { Epoxy } \\
(\mathbf{w t} \%)\end{array}$ & $\begin{array}{c}\text { Filler } \\
(\mathbf{w t} \%)\end{array}$ & $\begin{array}{c}\text { Density } \\
\left(\mathbf{g} / \mathbf{c m}^{\mathbf{3}}\right)\end{array}$ & $\begin{array}{c}\text { Hardness } \\
(\mathbf{b a r c o l})\end{array}$ \\
\hline $\begin{array}{c}\text { Carbon-epoxy (C-E) } \\
\begin{array}{c}\text { Graphite filled } \\
\text { carbon-epoxy (5G-C-E) }\end{array}\end{array}$ & 40 & - & 1.412 & 73 \\
$\begin{array}{c}\text { Graphite filled } \\
\text { carbon-epoxy (10G-C-E) }\end{array}$ & 30 & 10 & 1.465 & 76 \\
\hline
\end{tabular}




\subsection{Three-Body Wear Test}

Three-body abrasive wear experiment was conducted using dry sand/rubber wheel abrasion test set up as per ASTM G65 standard [27]. The schematic diagram of the test set up is shown in Figure 1.

Initially the samples were cleaned with acetone, dried and its initial weight was determined using a high precision digital electronic balance (0.0001 g accuracy). The naturally deposited silica sand of grain size $212 \mu \mathrm{m}$ in angular particle shape was used as abrasive. The abrasive was fed at the contacting face between the rotating rubber wheel and test sample. The tests were conducted at a rotational speed of $200 \mathrm{rpm}$. The rate of feeding abrasive was maintained at $255 \pm 5 \mathrm{~g} / \mathrm{min}$. The parameters and levels are given in Table 2. The experiment was carried out for three loads viz., $11 \mathrm{~N}, 23 \mathrm{~N}$ and $35 \mathrm{~N}$. The abrading distances were maintained at $300 \mathrm{~m}, 600 \mathrm{~m}$ and $900 \mathrm{~m}$. After testing, the specimens were removed, cleaned, dried and again weighed. The difference between the initial weight and final weight of the specimen was computed, this gives the material wear in terms of weight loss, was then converted into volume loss using measured density data. Further specific wear rate $\left(K_{s}\right)$ was calculated from equation [28]:

$$
K_{s}=\frac{\Delta V}{L \times D} \mathrm{~m}^{3} / \mathrm{N} \cdot \mathrm{m}
$$

where; $\Delta V$ is the volume loss in $\mathrm{m}^{3}, L$ is the load in Newton and $D$ is the abrading distance in meters.

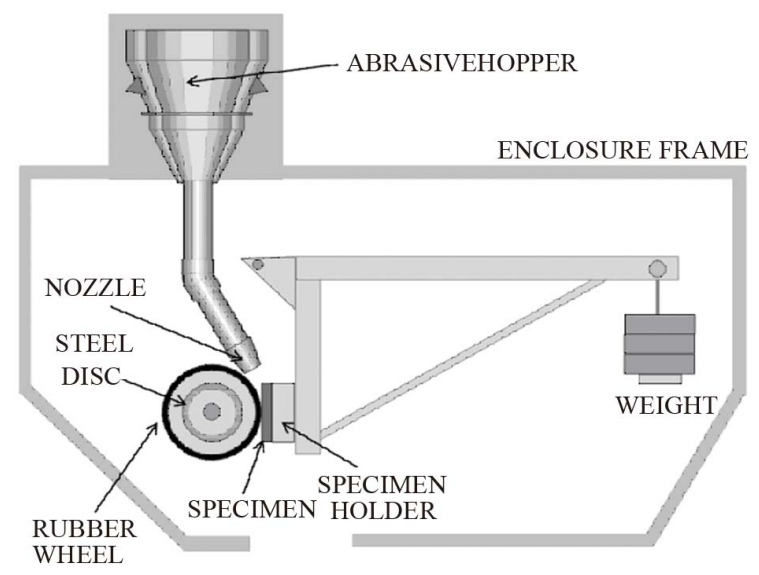

Figure 1. Dry sand/rubber wheel abrasive test rig.

Table 2. Control factors and levels.

\begin{tabular}{ccccc}
\hline Factor & Description & Level 1 & Level 2 & Level 3 \\
\hline A & Filler (wt\%) & 0 & 5 & 10 \\
B & Load (N) & 11 & 23 & 35 \\
C & Sliding distance (m) & 300 & 600 & 900 \\
\hline
\end{tabular}

In unlubricated sliding wear the value of wear coefficient $(k)$ is the dimensionless quotient [29] of the specimens was calculated according to the equation:

$$
k=\frac{\Delta V H}{L D}
$$

where $\Delta V$ is volumetric wear, $H$ is hardness of the wearing material, $L$ is the normal load in Newton, and $D$ is abrading distance in metres.

\subsection{Design of Experiments}

Wear properties are highly dependent on its material composition and variables under which it has to be performed [30]. This study was selected as the target qualities for optimization of the weight loss of composite material using 212 grain size silica sand of angular shape as abrasive. Three body abrasive wear test were conducted to determine weight loss. Taguchi uses a special design of orthogonal arrays to study the entire process parameter space with only a small number of experiments [31-33]. Twenty seven experimental runs, based on Taguchi orthogonal arrays were used to find the best factor level condition given in Table 3. The factor levels were assessed according to selected wear loss. The influence of the controllable process factors on the weight loss was studied, based on the correlation between the process factors. By analyzing the grey relational grade matrix, the most influential factors were identified. Finally the worn surfaces were observed by scanning electron microscopy (SEM) to understand wear mechanisms.

\subsection{Grey System}

Deng [34] proposed Grey relational analysis (GRA) which is part of grey system. GRA is suitable for solving problems with complicated inter relationships between multiple factors and variables. According to Moran et al. [35] grey relational analysis solves multi-attribute decision making problems by combing the entire range of performance attribute values being considered for every alternative into one single value. This reduces the original problem into a single decision making problem. This method quantifies the influences of various factors and their relation which is called the whitening of factor relation. The information that is either incomplete or undetermined is called grey. The system having incomplete information is called grey system. Grey based Taguchi method follows the optimization method developed by Dr. Genichi Taguchi. Taguchi method works for optimization of a single performance characteristic. GRA is used to combine the entire considered performance characteristic in optimization problem [36]. Grey relational analysis requires less data and can analyze many factors that can overcome the disadvantages of statistical methods. 
Table 3. Experimental layout using $\mathbf{L}_{27}\left(3^{13}\right)$ orthogonal Array and performance results.

\begin{tabular}{|c|c|c|c|c|c|c|}
\hline Expt. No. & Load, $A(\mathrm{~N})$ & Distance, $B(\mathrm{~m})$ & Filler, C (wt\%) & $\begin{array}{c}\text { Specific wear rate } \\
\left(K_{s}\right) \times 10^{-5}\left(\mathbf{m}^{3} / \mathbf{N} \cdot \mathbf{m}\right)\end{array}$ & $\begin{array}{l}\text { Wear coef. } \\
(k) \times 10^{-3}\end{array}$ & Hardness $(H)$ \\
\hline 1 & 11 & 300 & 0 & 6.6545 & 6.1887 & 73 \\
\hline 2 & 11 & 300 & 5 & 6.312 & 5.9333 & 74 \\
\hline 3 & 11 & 300 & 10 & 5.2757 & 5.0647 & 76 \\
\hline 4 & 11 & 600 & 0 & 3.6818 & 3.424 & 73 \\
\hline 5 & 11 & 600 & 5 & 3.3984 & 3.1945 & 74 \\
\hline 6 & 11 & 600 & 10 & 3.1696 & 3.0429 & 76 \\
\hline 7 & 11 & 900 & 0 & 2.6615 & 2.4753 & 73 \\
\hline 8 & 11 & 900 & 5 & 2.4282 & 2.2825 & 74 \\
\hline 9 & 11 & 900 & 10 & 2.2737 & 2.1827 & 76 \\
\hline 10 & 23 & 300 & 0 & 3.6898 & 3.4315 & 73 \\
\hline 11 & 23 & 300 & 5 & 3.2492 & 3.0543 & 74 \\
\hline 12 & 23 & 300 & 10 & 3.1115 & 2.9871 & 76 \\
\hline 13 & 23 & 600 & 0 & 1.9854 & 1.8465 & 73 \\
\hline 14 & 23 & 600 & 5 & 1.7782 & 1.6715 & 74 \\
\hline 15 & 23 & 600 & 10 & 1.7057 & 1.6375 & 76 \\
\hline 16 & 23 & 900 & 0 & 1.4801 & 1.3765 & 73 \\
\hline 17 & 23 & 900 & 5 & 1.3226 & 1.2433 & 74 \\
\hline 18 & 23 & 900 & 10 & 1.183 & 1.1357 & 76 \\
\hline 19 & 35 & 300 & 0 & 2.7257 & 2.5349 & 73 \\
\hline 20 & 35 & 300 & 5 & 2.3876 & 2.2443 & 74 \\
\hline 21 & 35 & 300 & 10 & 2.2076 & 2.1193 & 76 \\
\hline 22 & 35 & 600 & 0 & 2.0547 & 1.9109 & 73 \\
\hline 23 & 35 & 600 & 5 & 1.6923 & 1.5908 & 74 \\
\hline 24 & 35 & 600 & 10 & 1.5114 & 1.4509 & 76 \\
\hline 25 & 35 & 900 & 0 & 1.7698 & 1.6459 & 73 \\
\hline 26 & 35 & 900 & 5 & 1.3346 & 1.2545 & 74 \\
\hline 27 & 35 & 900 & 10 & 1.1892 & 1.1416 & 76 \\
\hline
\end{tabular}

\section{Results and Discussion}

\subsection{Abrasive Wear Volume}

The wear volume of unfilled C-E, 5G-C-E and 10G-C-E composites tested with varying load $11 \mathrm{~N}, 23 \mathrm{~N}$ and $35 \mathrm{~N}$ are shown in Figures 2(a)-(c). The wear volume tends to increase with increasing abrading distance from $300 \mathrm{~m}$ to $900 \mathrm{~m}$ as well load from $11 \mathrm{~N}$ to $35 \mathrm{~N}$. The higher filler loaded, $10 \mathrm{wt} \%$ graphite filled C-E exhibited lowest wear volume at all abrading distances and loads. Wear volume data revealed that wear volume of unfilled C-E at higher load is higher than that obtained at lower load. Severe damage to matrix and fiber is the main reason for higher wear at higher load. Higher contact pressure and elongation of softened matrix caused more debris and micro cracks in the matrix. Softened polymer matrix could not effectively protect the carbon fiber from peeling off which aggravated the fiber removal. This resulted in the decline of the wear resistance of unfilled C-E composite.
Additions of graphite filler considerably decreased the wear volume.

\subsection{Data preprocessing}

Data pre-processing is a process of transferring original sequence to a comparable sequence. For this experimental research, data is normalized between zero and one. Depending on characteristics of data sequence various methodologies of data pre-processing available. In this study the response to be optimized is specific wear rate, wear coefficient and Hardness.

To obtain the optimal wear performance lower-thebetter quality characteristic has been used to minimize the specific wear rate and wear coefficient, and can be expressed as:

$$
x_{i}^{*}(k)=\frac{\max x_{i}(k)-x_{i}(k)}{\max x_{i}(k)-\min x_{i}(k)}
$$

where $x_{i}^{*}(k)$ and $x_{i}(k)$ are sequences after data pre- 
processing and comparability sequence respectively, $k=$ 1,2 for wear rate and wear coefficient. $i=1,2,3, \cdots, 27$ for experiment number 1 to 27.

Hardness of composite should follow higher-the better criterion which can be expressed as:

$$
x_{i}^{*}(k)=\frac{x_{i}(k)-\min x_{i}(k)}{\max x_{i}(k)-\min x_{i}(k)}
$$

where $x_{i}^{*}(k)$ and $x_{i}(k)$ are sequences after data pre-pro- cessing and comparability sequence respectively, $k=3$ for hardness. $i=1,2,3, \cdots, 27$ for experiment number 1 to 27 .

$\Delta_{o i}(k)$ is deviation sequence of reference sequence $x_{0}^{*}(k)$ and comparability sequence $x_{i}^{*}(k)$. Deviation sequence $\Delta_{o i}$ can be calculated using equation:

$$
\Delta_{o i}(k)=\left|x_{o}^{*}(k)-x_{i}^{*}(k)\right|
$$

Table 4 represents the normalized data and deviation sequence for 27 experimental runs.
$11 \mathrm{~N}$

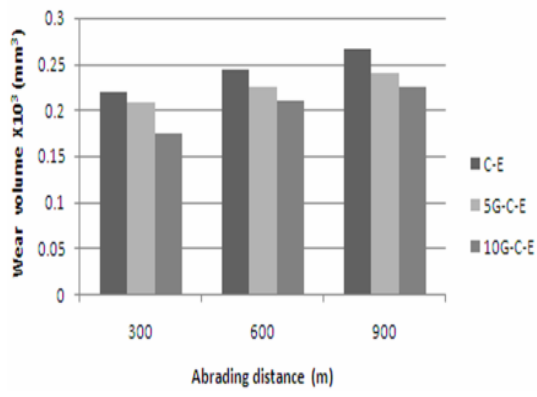

(a)

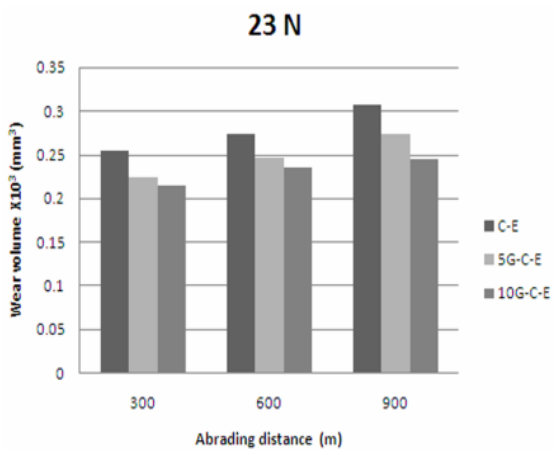

(b)

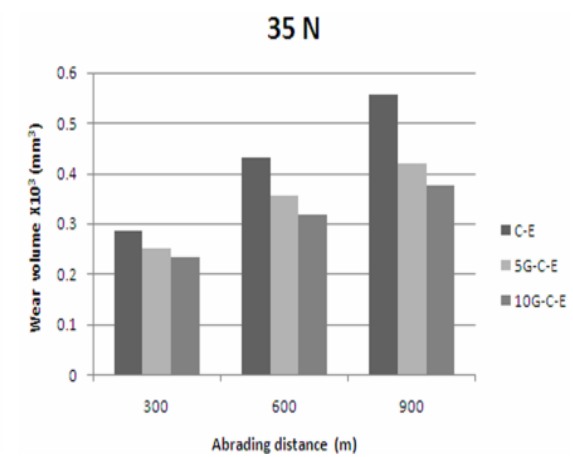

(c)

Figure 2. Effect of abrading distance on wear volume of composites at (a) $11 \mathrm{~N}$; (b) $23 \mathrm{~N}$; (c) $35 \mathrm{~N}$.

\begin{tabular}{|c|c|c|c|c|c|c|}
\hline \multirow{2}{*}{$\begin{array}{c}\text { Expt } \\
\text { No. }\end{array}$} & \multicolumn{3}{|c|}{ Normalized data } & \multicolumn{3}{|c|}{ Deviation sequences $\left(\Delta_{o i}\right)$} \\
\hline & $K_{s} \times 10^{-4}$ & $(k) \times 10^{-3}$ & $\boldsymbol{H}$ & $K_{s} \times 10^{-4}$ & $(k) \times 10^{-3}$ & $\boldsymbol{H}$ \\
\hline 1 & 0.0000 & 0.0000 & 0.0000 & 1.0000 & 1.0000 & 1.0000 \\
\hline 2 & 0.0625 & 0.0505 & 0.3333 & 0.9375 & 0.9495 & 0.6667 \\
\hline 3 & 0.2519 & 0.2224 & 1.0000 & 0.7481 & 0.7776 & 0.0000 \\
\hline 4 & 0.5433 & 0.5471 & 0.0000 & 0.4567 & 0.4529 & 1.0000 \\
\hline 5 & 0.5951 & 0.5925 & 0.3333 & 0.4049 & 0.4075 & 0.6667 \\
\hline 6 & 0.6369 & 0.6225 & 1.0000 & 0.3631 & 0.3775 & 0.0000 \\
\hline 7 & 0.7297 & 0.7348 & 0.0000 & 0.2703 & 2652 & 1.0000 \\
\hline 8 & 0.7724 & 0.773 & 0.3333 & 0.2276 & 0.227 & 0.6667 \\
\hline 9 & 0.8006 & 0.7927 & 1.0000 & 0.1994 & 0.2073 & 0.0000 \\
\hline 10 & 0.5418 & 0.5456 & 0.0000 & 0.4582 & 0.4544 & 1.0000 \\
\hline 11 & 0.6223 & 0.6203 & 0.3333 & 0.3777 & 0.3797 & 0.6667 \\
\hline 12 & 0.6475 & 0.6336 & 1.0000 & 0.3525 & 0.3664 & 0.0000 \\
\hline 13 & 0.8533 & 0.8593 & 0.0000 & 0.1467 & 0.1407 & 1.0000 \\
\hline 14 & 0.8912 & 0.8939 & 0.3333 & 0.1088 & 0.1061 & 0.6667 \\
\hline 15 & 0.9044 & 0.9006 & 1.0000 & 0.0956 & 0.0994 & 0.0000 \\
\hline 16 & 0.9457 & 0.9523 & 0.0000 & 0.0543 & 0.0477 & 1.0000 \\
\hline 17 & 0.9744 & 0.9787 & 0.3333 & 0.0256 & 0.0213 & 0.6667 \\
\hline 18 & 1.0000 & 1.0000 & 1.0000 & 0.0000 & 0.0000 & 0.0000 \\
\hline 19 & 0.7180 & 0.7230 & 0.0000 & 0.2820 & 0.2770 & 1.0000 \\
\hline 20 & 0.7798 & 0.7806 & 0.3333 & 0.2202 & 0.2194 & 0.6667 \\
\hline 21 & 0.8127 & 0.8053 & 1.0000 & 0.1873 & 0.1947 & 0.0000 \\
\hline 22 & 0.8406 & 0.8465 & 0.0000 & 0.1594 & 0.1535 & 1.0000 \\
\hline 23 & 0.9069 & 0.9099 & 0.3333 & 0.0931 & 0.0901 & 0.6667 \\
\hline 24 & 0.9399 & 0.9376 & 1.0000 & 0.0601 & 0.0624 & 0.0000 \\
\hline 25 & 0.8927 & 0.899 & 0.0000 & 0.1073 & 0.1010 & 1.0000 \\
\hline 26 & 0.9722 & 0.9764 & 0.3333 & 0.0278 & 0.0236 & 0.6667 \\
\hline 27 & 0.9988 & 0.9988 & 1.0000 & 0.0012 & 0.0012 & 0.0000 \\
\hline
\end{tabular}

Table 4. Normalized data and deviation sequences. 


\subsection{Grey Relational Coefficient and Grey Relational Grade}

Grey relational coefficient (GRC) expresses relationship between ideal and actual normalized experimental results and is given by:

$$
\xi_{i}(k)=\frac{\Delta_{\min }+\zeta \Delta_{\max }}{\Delta_{o i}(k)+\zeta \Delta_{\max }}
$$

where $\Delta_{o i}(k)$ is deviation sequence of reference sequence $x_{0}^{*}(k)$ and comparability sequence is $x_{i}^{*}(k), \zeta$ distinguishing or identification coefficient. The purpose of grey relational coefficient is to expand or compress the range of grey relational coefficient [37]. If all parameters are given equal preference, $\zeta$ is taken as 0.5 . Grey relational coefficient (GRC) Table 5 for each experiment can be calculated using Equation (6).

After obtaining GRC, the Grey relational grade (GRG) is computed by averaging GRC corresponding to each performance characteristic. Overall evaluation of multiple performances characteristic is based on GRG is given by:

$$
\gamma_{i}=\frac{1}{n} \sum_{k=1}^{n} \xi_{i}(k)
$$

Table 5. Grey relational coefficient and grey relational

\begin{tabular}{|c|c|c|c|c|}
\hline \multirow{2}{*}{ Expt. No } & \multicolumn{3}{|c|}{ Grey Relational Coefficient } & \multirow{2}{*}{ GRG } \\
\hline & $K_{s}$ & $\boldsymbol{k}$ & $\boldsymbol{H}$ & \\
\hline 1 & 0.3333 & 0.3333 & 0.3333 & 0.3333 \\
\hline 2 & 0.3478 & 0.3449 & 0.4285 & 0.3737 \\
\hline 3 & 0.4006 & 0.3913 & 1.0000 & 0.5973 \\
\hline 4 & 0.5226 & 0.5247 & 0.3333 & 0.4602 \\
\hline 5 & 0.5525 & 0.5509 & 0.4285 & 0.5106 \\
\hline 6 & 0.5793 & 0.5698 & 1.0000 & 0.7163 \\
\hline 7 & 0.6490 & 0.6534 & 0.3333 & 0.5452 \\
\hline 8 & 0.6871 & 0.6877 & 0.4285 & 0.6011 \\
\hline 9 & 0.7148 & 0.7069 & 1.0000 & 0.8072 \\
\hline 10 & 0.5218 & 0.5238 & 0.3333 & 0.4596 \\
\hline 11 & 0.5696 & 0.5683 & 0.4285 & 0.5221 \\
\hline 12 & 0.5865 & 0.5771 & 1.0000 & 0.7217 \\
\hline 13 & 0.7731 & 0.7803 & 0.3333 & 0.6289 \\
\hline 14 & 0.8212 & 0.8249 & 0.4285 & 0.6915 \\
\hline 15 & 0.8394 & 0.8341 & 1.0000 & 0.8911 \\
\hline 16 & 0.9020 & 0.9129 & 0.3333 & 0.7478 \\
\hline 17 & 0.9512 & 0.9591 & 0.4285 & 0.7796 \\
\hline 18 & 1.0000 & 1.0000 & 1.0000 & 1.0000 \\
\hline 19 & 0.6393 & 0.6435 & 0.3333 & 0.5387 \\
\hline 20 & 0.6942 & 0.695 & 0.4285 & 0.6059 \\
\hline 21 & 0.7274 & 0.7197 & 1.0000 & 0.8157 \\
\hline 22 & 0.7582 & 0.7651 & 0.3333 & 0.6188 \\
\hline 23 & 0.8430 & 0.8473 & 0.4285 & 0.7062 \\
\hline 24 & 0.8926 & 0.889 & 1.0000 & 0.9272 \\
\hline 25 & 0.8233 & 0.8319 & 0.3333 & 0.6628 \\
\hline 26 & 0.9473 & 0.9549 & 0.4285 & 0.7769 \\
\hline 27 & 0.9976 & 0.9976 & 1.0000 & 0.9984 \\
\hline
\end{tabular}
grade.
It is evident from the Table 5 that experiment 18 has the best multiple performance characteristic among the twenty seven experiments since having the highest grey relational grade. The process parameters are converted in to signal to noise ratio. Figure 3, graphically representsthe effect of three control factor in GRG. The combination factor that optimizes wear process was identified as A3B3C3. Parameter combination of $10 \mathrm{wt} \%$ graphite filled carbon-epoxy composite abraded for $900 \mathrm{~m}$ under a load of $35 \mathrm{~N}$ results in least wear. Total mean of grey relational grade for twenty seven experiments are given in Table 6. The rank in the last column of the table represents the significance of each parameter.

\subsection{Analysis of Variance}

The purpose of analysis of variance (ANOVA) is to investigate parameters which significantly affect the performance characteristic. This is established by separating the total variability of the grey relational grades, which is measured by sum of the squared deviations from the total mean of the grey relational grade, into contributions by each wear parameters and listed in Table 7.

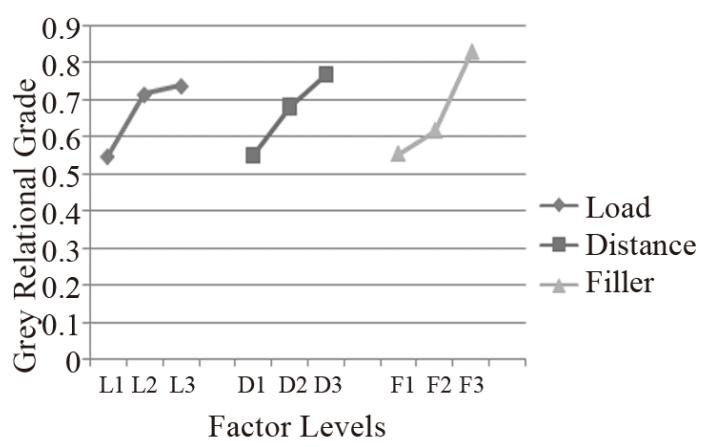

Figure 3. Effect of wear process parameter levels on grey relational grade.

Table 6. Response table for grey relational grade.

\begin{tabular}{ccccccc}
\hline \multirow{2}{*}{ Symbol Parameter } & \multicolumn{3}{c}{ GRG } & \multicolumn{1}{c}{$\begin{array}{c}\text { Main effect } \\
\text { (max - min) }\end{array}$} & Rank \\
\cline { 3 - 7 } & Level 1 & Level 2 & Level 3 & & \\
\hline A & Load & 0.5494 & 0.7158 & 0.7390 & 0.1895 & 3 \\
B & Distance & 0.5520 & 0.6834 & 0.7688 & 0.7688 & 2 \\
C & Filler & 0.5550 & 0.6186 & 0.8305 & 0.2755 & 1 \\
\hline
\end{tabular}

Table 7. ANOVA results.

\begin{tabular}{ccccc}
\hline Symbol & Parameter & DOF & Sum of Square Contribution \% \\
\hline A & Load & 2 & 0.192408 & 24.170 \\
B & Distance & 2 & 0.214650 & 26.970 \\
C & Filler & 2 & 0.374583 & 47.070 \\
A $*$ B & Load*Distance & 4 & 0.010234 & 1.290 \\
A $*$ C & Load*Filler & 4 & 0.002567 & 0.322 \\
B*C & Distance*Filler & 4 & 0.000220 & 0.028 \\
Error & & 8 & 0.001202 & 0.150 \\
\hline
\end{tabular}


According to ANOVA the percentage of contributions indicate the relative power of a factor to reduce variation. The factor with high percent contribution has greatest influence on the performance. The percentage contribution of filler content $(47.07 \%)$ was found to be the major factor affecting the wear performance. Whereas the abrading distance $(26.97 \%)$ found to be second influential factor followed by Load (24.17\%) as shown in Figure 4. Suresha et al. [38] investigated the effect of $\mathrm{SiC}$ filler addition on two-body abrasive wear and concluded that the maximum wear resistance was obtained for $7.5 \mathrm{wt} \%$ $\mathrm{SiC}$ in G-E composite. The present work data by Grey relational analysis are in good agreement with the experimental investigations.

\subsection{Surface Morphology}

The worn surface of unfilled C-E composite Figures 5(a) and (b), 10\% graphite filled C-E composite Figures 6(a) and (b) are examined foe two loads $11 \mathrm{~N}$ and $35 \mathrm{~N}$ at 900 $\mathrm{m}$ abrading distance. Unfilled C-E sample Figure 5(a) showed higher degree of worn surface features compared to $10 \%$ graphite filled Figure 5(b). The same observations hold good for samples subjected to higher load of $35 \mathrm{~N}$ shown in Figures 6(a) and (b). These are supportive to wear volume shown in Figure 2. Filled C-E composites

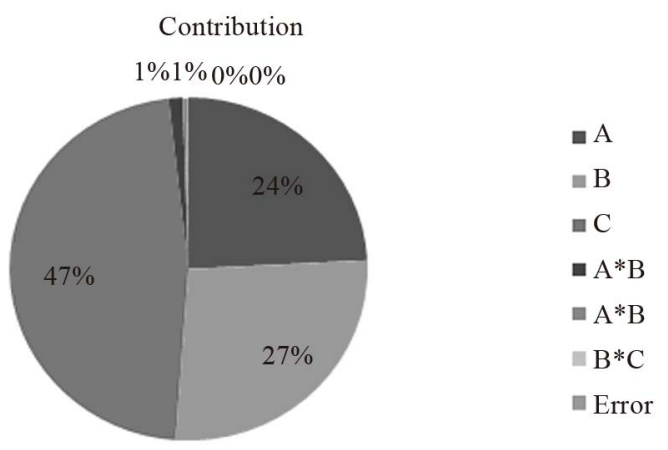

Figure 4. Percentage contribution of factors on grey relational grade.

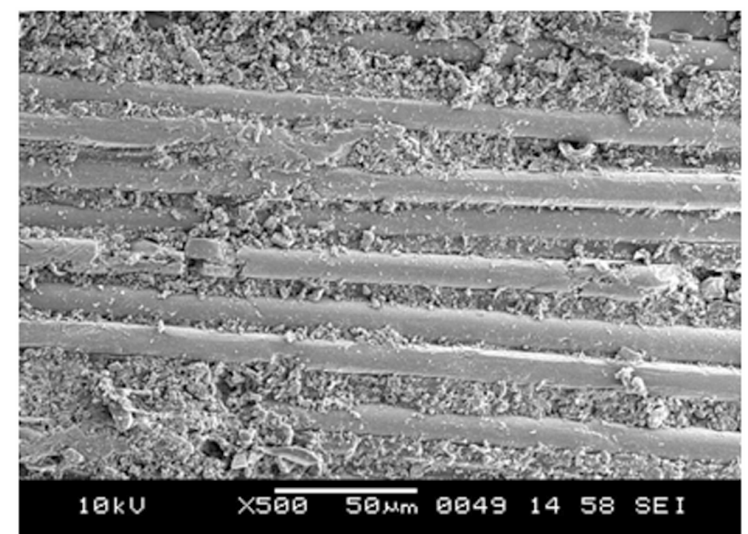

(a)

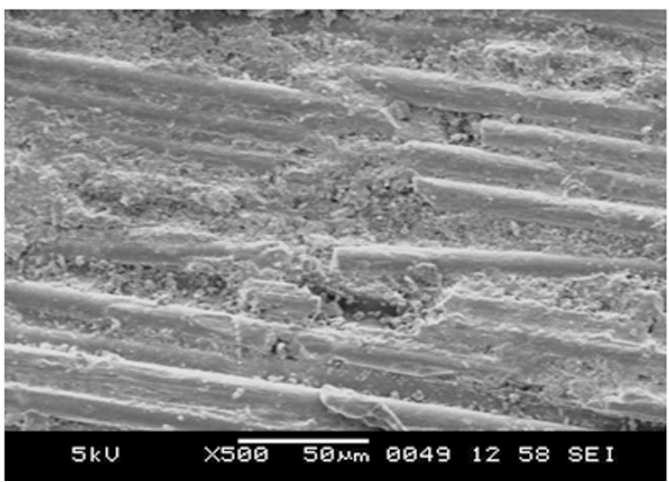

(b)

Figure 5. SEM micrograph of worn surface of unfilled C-E subjected to load (a) $11 \mathrm{~N}$; (b) $35 \mathrm{~N}$.

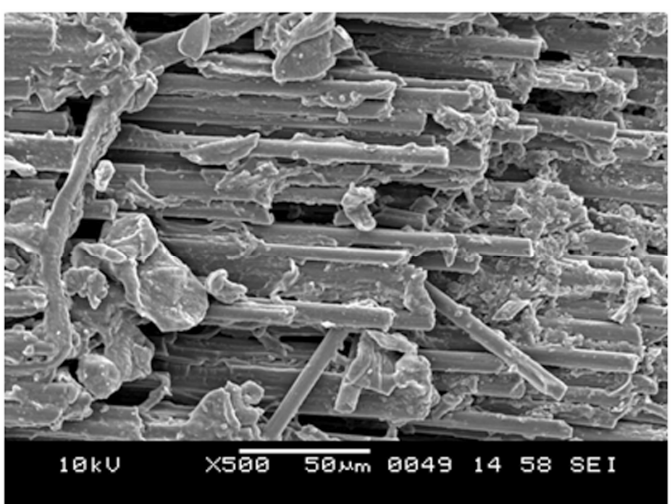

(a)

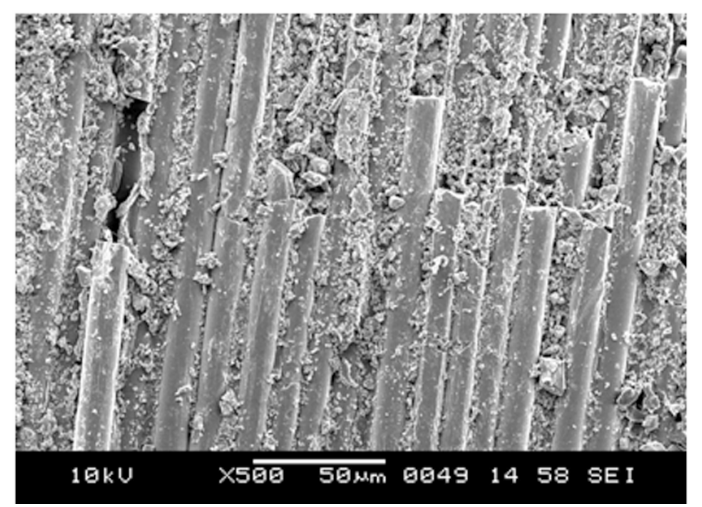

(b)

Figure 6. SEM micrograph of worn surface of $10 \mathrm{wt} \%$ graphite filled C-E subjected to (a) $11 \mathrm{~N}$; (b) $35 \mathrm{~N}$.

at a load of $11 \mathrm{~N}$, exhibited number of broken fiber with minimum debris as compared to unfilled C-E composites. Filled C-E composites subjected to higher load of $35 \mathrm{~N}$, markings of fibers were noticed where as unfilled C-E Figure 5(b) show large number of broken fibers with lot of distortion in the matrix with higher degree of debris formation. The application of higher load has resulted in the deformation in the form of disorientation of fibers perpendicular to the abrading direction. 


\section{Conclusions}

The grey based Taguchi multi response method was applied in this study to optmize the three-body abrsive wear of unfilled and graphite filled carbon-epoxy composites. The results are summarized as follows:

- Taguchi method, a simple systematic and efficient methodolgy used for optimizing three control factors to set optimal levels for meeting the objective with minimum number of experimental runs, to study the abrasive wear characteristics of composites.

- Optimal wear parameters have been determined by Grey relational grade for multiperformance charateristics: specific wear rate, wear coefficient and hardness.

- ANOVA of GRG for multiperformance charateristics revealed that factors like filler content $(\mathrm{C})$, abrading distance (B) and applied load (A) are significant in order of priority to minimize the wear.

- Controlling factors with $\mathrm{A} 3 \mathrm{~B} 3 \mathrm{C} 3$ combination caused minmum wear and higer hardness.

- Graphite filler found to possess good filler characteristics and increases the wear resistance of C-E composite.

\section{REFERENCES}

[1] C.-P. Fung, "Manufacturing Process Optimization for Wear Property of Fiber Reinforced Polybutylene Terephthalate Composites with Grey Relational Analysis," Wear, Vol. 254, No. 3-4, 2003, pp. 298-306. doi:10.1016/S0043-1648(03)00013-9

[2] B. Suresha, G. Chandramohan and P. V. Mohanram, "Role of Fillers on Three Body Abrasive Wear Behavior of Glass Fabric Reinforced Epoxy Composites," Polymer Composites, Vol. 10, No. 8, 2009, pp. 1106-1113. doi:10.1002/pc. 20662

[3] M. Cirino, K. Friedric and P. B. Pipes, "Effect of Fiber Orientation on the Abrasive Wear Behavior of Polymer Composite Materials," Wear, Vol. 121, No. 2, 1998, pp. 127-135. doi:10.1016/0043-1648(88)90038-5

[4] Z. Lu and A. M. Hager, "Recent Advances in Polymer Composites," Tribology, Vol. 190, 1996, pp. 139-144.

[5] A. A. El-Sayed, M. G. El-Sherbiny, A. S. Abo-EL-Ezz, G. A. Aggag, "Friction and Wear Properties of Polymeric Composite Materials for Bearing Applications," Wear, Vol. 184, No. 1, 1995, pp. 45-53.

doi:10.1016/0043-1648(94)06546-2

[6] B. Suresha, Siddaramaiah, Kishor, S. Seetharamu and P. Sampath Kumaran, "Investigations on the Graphite Filler on Dry Sliding Wear and Abrasive Wear Behavior of Carbon Fabric Reinforced Epoxy Composites," Wear, Vol. 267, No. 9-10, 2009, pp. 1405-1414.

[7] H. W. Chang, "Correlation of Wear with Oxidation of Carbon-Carbon Composites," Wear, Vol. 80, No. 9-10, 2009, pp. 7-14. doi:10.1016/0043-1648(82)90083-7

[8] C. Lhymn, "Tribological Behavior of Unidirectional Polyphenylene Sulphide Carbon Fiber Reinforced Lami- nate Composites," Wear, Vol. 117, No. 2, 1987, pp. $343-$ 359.

[9] B. S. Tripaty and M. J. Furey, "Tribological Behavior of Unidirectional Graphite Epoxy and Carbon-PEEK Composites," Wear, Vol. 162, 1993, pp. 343-359.

[10] J. K. Lancaster, "The Effect of Carbon Fiber Reinforcement on Friction and Wear of Polymer," Applied Physics, Vol. 1, 1968, pp. 549-555.

[11] P. B. Mody, T. W. Chan and K. Friedrich, "Effect of Testing Condition and Microstructures on the Sliding Wear of Graphite Fiber/Peek Matrix Composites," Journal of Materials Science, Vol. 23, No. 12, 1998, pp. 43194330. doi:10.1007/BF00551926

[12] S. Chand, "Review Carbon Fibers for Composites," Journal of Materials Science, Vol. 35, No. 6, 2000, pp. 1303-1313. doi:10.1023/A:1004780301489

[13] Y. J. Shi, X. Feng, H. Y. Wang and X. H. Lu, "Tribological Properties of PTFE Composites Filled with Surface Treated Carbon Fiber," Journal of Materials Science, Vol. 42, No. 20, 2007, pp. 8465-8469. doi:10.1007/s10853-007-1767-7

[14] J. Bijwe and R. Rattan, "Carbon Fabric Reinforced Polyetherimide Composite: Optimization of Fabric Content for Best Combination of Strength and Adhesive Wear Performance," Wear, Vol. 262, 2007, pp. 749-758.

[15] X. Cheng, Y. Xue and C. Xie, "Tribological Investigation of PTFE, Composite Filled with Lead and Rare EarthModified Glass Fiber," Materials Letters, Vol. 57, 2003, pp. 2553-2557.

[16] B. Suresha, Siddaramaih, Kishoe, S. Seetharamu and P. Sampathkumaran, "Influence of Graphite Filler on Dry Siding Wear of Carbon Fabric Reinforced Epoxy Composites," Wear, Vol. 267, No. 9-10, pp. 1405-1414. doi:10.1016/j.wear.2009.01.026

[17] B. Suresha, B. N. Ramesh, K. M. Subbaya, B. N. Ravikumar and G. Chandramohan, "Influence of Graphite Filler on Two Body Abrasive Wear Behavior of Carbon Fabric Reinforced Epoxy Composite," Materials and Design, Vol. 31, No. 4, 2010, pp. 1833-1841. doi:10.1016/i.matdes.2009.11.006

[18] B. Suresha, B. N. Ramesh, K. M. Subbaya and G. Chandramohan, "Mechanical and Three Body Abrasive Wear Behavior of Carbon Epoxy Composite with and Without Graphite Filler," Journal of Composite Materials, Vol. 44, No. 21, 2010, pp. 2509-2519. doi:10.1177/0021998310369589

[19] Q. Z. Zhang, Y. W. Liu, Y. D. Huang, L. Liu and J. W. Bao, "The Effect of Carbon Fiber Surface Properties and Electron Beam Curing of Epoxy Resin Composites," Composites Science and Technology, Vol. 62, No. 3, 2002, pp. 331-337. doi:10.1016/S0266-3538(01)00222-6

[20] W. Qin, Z. Q. Zhang and X. H. Wu, "Effect of Cold Plasma Treatment on the Mechanical Properties of RTM Component," Journal of Materials Science and Technology, Vol. 19, 2003, pp. 281-286.

[21] K. Anthony, "Composite Materials," Journal of Ceramic Processing Research, Vol. 2, 2001, pp. 147-154.

[22] M. Cirino, K. Friedrich and R. B. Pipes, "The Abrasive 
Wear Behavior of Continuous Fiber Polymer Composites," Journal of Materials Science, Vol. 22, No. 7, 1987, pp. 235-247. doi:10.1007/BF01082134

[23] X. H. Cheng, Y. J. Xue and C. Y. Xie, "Friction and Wear of Rare-Earth Modified Glass Fiber Filled PTFE Composites in Dry Reciprocating Sliding Motion with Impact Loads," Wear, Vol. 253, No. 7-8, 2002, pp. 869877. doi:10.1016/S0043-1648(02)00217-X

[24] G. Taguchi and S. Konishi, "Taguchi Methods: Orthogonal Arrays and Linear Graphs," American Supplier Institute Inc., Dearborn, 1987.

[25] G. Taguchi, "Introduction to Quality Engineering," Asian Productivity, Tokyo, 1990.

[26] ASTM D2583, "Standard Test Method for Indentation Hardness of Rigid Plastic by Means of a Barcol Impresser," 2007.

[27] ASTM G65, "Standard Test Method for Wear Testing with a Dry sand Abrasive Test Apparatus," 2010.

[28] A. Ravikiran, "Wear Quantification," ASME, Vol. 122, 2000, pp. 650-656.

[29] K. H. Zum Gahr, "Wear by Hard Particles," Tribology international, Vol. 31, No. 10, 1998, pp. 587-596. doi:10.1016/S0301-679X(98)00079-6

[30] S. S. Mahapatra and S. Datta, "A Grey Based Taguchi Method for Wear Assessment of Red Mud Filled Polyester Composites," International Journal of Modeling and Optimization, Vol. 1, No. 1, 2011, pp. 80-88.

[31] C. Hung, C.-L. Chang and L. Chen, "Applying Grey Relational Analysis to the Wender Evaluation Model," International Journal of the Computer and the Internet and
Management, Vol. 11, No. 3, 2003, pp. 45-53.

[32] C.-L. Yang, "Optimizing the Glass Fiber Cutting Process Using the Taguchi Methods and Grey Relational Analysis," New Journal of Glass and Ceramics, Vol. 1, 1987, pp. 13-19.

[33] K. H. Chang and C. S. Wu, "A Grey Time Series Model on Forecasting the Chinese Near Year Effect in the Taiwan Stock Market," Journal of Grey System, Vol. 8, No. 3, 1996, pp. 235-260.

[34] J. Deng, "Introduction to Grey System," Journal of Grey System, Vol. 1, 1989, pp. 1-24.

[35] J. Moran, E. Granada, J. L. Miguez and J. Poterio, "Use of Grey Relational Analysis to Asses and Optimize Small Biomass Boilers," Fuel Processing Technology, Vol. 87, No. 2, 2006, pp. 123-127.

[36] S. Biswas and A. Satpathy, "Tribo Performance Analysis of Red Mud Filled Glass-Epoxy Composites Using Taguchi Experimental Design," Materials and Design, Vol. 30, 2009, pp. 2841-2853.

[37] Y. Kuo, T. Yang and G.-W. Huang, "The Use of Grey Based Taguchi Method for Optimizing Multiresponse Optimization Problems," Engineering Optimization, Vol. 4, No. 6, 2008, pp. 517-528. doi:10.1080/03052150701857645

[38] B. Suresha, G. Chandramohan, J. P. Prakash, V. Balusamy and K. Shankaranarayanasamy, "Role of Fillers on Friction and Slide Wear Characteristics in Glass-Epoxy Composite System," Journal of Minerals Materials Characterization and Engineering, Vol. 5, No. 1, 2006, pp. 87110. 